\title{
Semantic modelling of self-realization of the personality
}

\author{
Sergey Ivanovich Dyakov
}

Sevastopol State University. Department of Psychology. Sevastopol (Russia)

Título: Modelado semántico de la autorrealización de la personalidad. Resumen: Introducción. La investigación se centra en estudiar la autoorganización de la personalidad en el aspecto de la subjetividad. Se presenta la técnica de modelado de identificación social y de roles de la personalidad. El objetivo de la investigación consiste en definir constructos semánticos autoactualizables en el modelado de identificación personal.

Métodos y técnicas de una investigación. Se utiliza un enfoque semántico en la estructuración de parejas dicotomizadoras de constructos de identificación personal, con la técnica original "Modelado Semántico de Autoorganización de la Personalidad" ("SMSOP"). Los encuestados cumplimentan la rejilla de J. Kelly. Los resultados de la muestra se factorizan. Los encuestados modelan en imágenes "Yo soy-real", "Yo soy-ideal" y también imágenes de "La Personalidad Auto-actualizada" (SUP) y "No conformista" (NC), utilizando un conjunto de constructos lingüísticos recibidos mediante el repertorio reticular de J. Kelly. La muestra consta de 218 personas (estudiantes psicólogos).

Resultados y discusión. Se muestran datos comparativos de los constructos autoactualizables (en el aspecto "Yo soy-ideal") y los modelos SUP y Oil Company. Aunque SUP es un modelo de referencia de los logros de la personalidad (según A. Maslow, etc.), y el NC revela propiedades de autoafirmación, en la semántica de la autoorganización mental (MSO) de la personalidad, los encuestados no están centrados plenamente en estos estándares. Los resultados del análisis factorial mostraron rasgos de la semántica de MSO de la identidad de los estudiantes en el aspecto de autoactualización ("Yo soy-ideal"): espontaneidad emocional y, al mismo tiempo, fortaleza de ánimo y autoconfianza y también comunicación y bienestar en la vida (relacionado con la intelectualidad, el ingenio).

Conclusiones. La semántica de las personas que se auto-actualizan revela a los jóvenes en las posiciones que definen aspectos posibles y alcanzables de la perspectiva de su vida. Los modelos SUP y NC son "perfectos" para ellos.

Keywords: Autoactualización. Inconformista. Autoorganización mental.

Modelado semántico. Constructos de identificación de la personalidad.

Subjetividad de la personalidad.
Abstract: Introduction. The research is focused on studying self-organization of the personality in aspect of subjectness. The technique of modeling of social and role identification of the personality is presented. The research objective - to define semantic constructs self-updating in modeling of personal identification.

Methods and techniques of a research. Semantic approach in structuring dichotomizing couples of constructs of personal identification is used. Offered original technique "Semantic Modelling of Self-organization of the Personality" ("SMSOP"). Respondents fill "Repertoire lattices" of J. Kelly. Results of sample are factorized. Respondents make modeling of in images "I amreal", "I am-ideal" and also images of "The Self-updated Personality" (SUP) and "Nonconformist" (NC), using a set of the linguistic constructs received by means of repertoire lattices of J. Kelly). Sample - studentspsychologists, the 218th persons.

Results and discussion. Comparative data of constructs self-updating (in aspect "I am-ideal") and the SUP and Oil Company models showed. Though SUP is a reference model of achievements of the personality (according to A. Maslow, etc.), and the NC discloses properties of self-affirmation, in semantics of mental self-organization (MSO) of the personality, respondents aren't focused fully on these standards. Results of the factorial analysis showed features of semantics of MSO of the identity of students in aspect self-updating ("I am-ideal"): emotional spontaneity and, at the same time, strength of mind and self-confidence and also communication and wellbeing in life (connected with intellectuality, ingenuity).

Conclusions. Semantics self-updating persons reveals for youth in the positions defining possible, achievable aspects of prospect of their life. The SUP and NC models are "perfect" for them.

Keywords: Self-updating. Nonconformist. Mental self-organization. Semantic modeling. Constructs of identification of the personality. Subjectness of the personality.

\section{Introduction}

Now, in psychological science, increasing number of researchers of a focused on studying the subject sphere of the personality in aspect of self-organization of behavior and lives activity, in that number and social relations (Brushlinsky, 2002; Dyakov, 2016a-c; Sergienko, 2003; Tatenko, 1996). Concept of the subject to an researchers connect with properties of self-motivated activity (Ryan et al, 2107), independence (Tatenko, 1996), self-determination (Whittingham, 2018), free will (Koestern et al, 2014) and creativity, and reflect in such types of the personality as the nonconformist, the self-updated personality etc. (Dyakov, 2016c). These characteristics and types disclose the modern post-nonclassical, phenomenological, existential and

* Correspondence address [Dirección para correspondencia]:

Dyakov Sergey Ivanovich. Sevastopol State University. Department of Psychology. 299018. Sevastopol, Gagarin Avenue, 13. (Russia).

E-mail: astropsiyoga@gmail.com

(Article received: 16-3-2021, revised: 20-5-2021, accepted: 14-9-2021) humanistic principles of understanding of the person in psychology and philosophies. The problem of self-updating is in whether the person as the subject is capable to make the choice, to make the decision and to form intention to overcome external difficulties and internal weakness (impulsiveness, reactivity, uneasiness) that creates conformality and indecision (Whittingham, 2018). Considering that the person lives in the typical environment, constancy of conditions of his life defines typicality of experience adaptation and sociocultural identification (Fogelson, 1982), and from here, typicality of a way of life and properties of the personality. Thus, the person as the personality self-organizes in process of the knowledge and determination of values and meanings of "things" in field of life. From here personality as subject in the mental information-semantic (cognitive and intellectual (understanding sociocultural values of things and life phenomena) and axiological (value-semantic orientations)) of self-organization focused by certain sociocultural standards and norms. 
Subject's paradigm and subjectness in psychology touches on an issue of a system understanding self-organization ontology and self-development "live" twisting IN intentional continuum lives (Dyakov, 2016c). This problem is widely reflected in to philosophy and science. The self-organization, category synthesized in synergetic is considered in aspect of transdisciplinary integration in development of complex intellectual systems today (Heylighen, 2011), where the subject loses the anthropological value (Whitehead et al, 2012). The cyberspace washes away identity and distinctions, forcing to rethink a concept of the subject (Whitehead et al, 2012). Nevertheless, we still are interested in aspects of the relation of the person to the world and life, its semantic structures in which foreshortening it as the subject defines the activity. It is no secret that it is connected with speech functions in a conceptual categorization of semantic constructs of conscious structuring and conceptualization of experience. Selforganization is considered in psychological systems in aspect of a meaning formation (Klochko, 2005).

Development of modern cognitive psychology and neuroscience updates a research of human language and the speech as highest achievements of the nature therefore the intelligence and consciousness developed. Researchers consider language as a self-organizing cognitive system which then materializes a thought in words (Clark, 2013). Actually, the brain is a predictive system (Bar, 2007; Barrett, 2009; Clark, 2013), which is under construction on the basis of individual experience in aspect of systematization of values in creation of semantic structure of life (Fodor). These aspects define the prospect of development of psychological science revealing in psychosemantics (Artemyeva, 1999; Fodor, 1987). Also, in researches the neuro and cognitive models opening are considered: communication of neuroscience with psychology (Levine, 2018); narrative representations of experience as generative models in hierarchical predictive data processing (Farmer et al, 2013; Hirsh et al, 2013). Interests scientists as culture in autobiographical (semantic) memory of the person is displayed (Wang et al, 2011) and also forecasting models in the system of scientific knowledge (Pirozhkova, 2018). These aspects of modeling of personal linguisticsemantic structures of sociocultural identification are relevant for our research. The modern psychology focused on the modeling paradigm (Bandura, 2017). It is relevant in aspect of understanding of a system of values in a categorization of structure of individual experience of the subject (Richardson et al, 2014). At the same time, progressive technologies in the field of informatics and cybernetics demand special researches of syntactic generative modeling of dependence in linguistic structure "predicate argument" (Clark, 2013; Hockenmaier, 2003). Also, the problem of digitalization of society requires the solution (Karakozov et al, 2019), which is connected with modeling of strategies of development for the personality and group including in educational space.

Today it is accepted to understand information the universal generator of self-organization of reality (Podoprigora,
2016). Basic researches in fields of physics and prove to cosmology that semantics Integra istivny, universal principle systemic organization of the world AND LIVES: D. Baume (Bom, 2010), L.V. Leskov (Groves, 2008), V.V. Nalimov semantic space of the Universe; V.I. Vernadsky - a noosphere. So it finds reflection in psychology: cemantic field of A. Menegetti; semantic theory of thinking of O.K. Tikhomirov; semantic models of individual mentality (neocognitive psychology) V.D. Shadrikova (Shadrikov, 2017); A.Yu. Agafonov is a person as semantic model of the world. On a row with it is developed anthropological mythcemantic (K. Levi-Stros and other), etc. This universality defines relevance of semantic approach in psychology of subjectness of the personality.

We consider semantics in psychology in a broad sense as a kernel of cognitive psychology (which unites psychology in information aspect of experience) (Dyakov, 2016c) that defines information and semantic criterion of mental selforganization (MSO) by means of which the categorizationconceptualization of systems of values and the semantic relations in self-organization of activity of the personality as the subject is carried out (Ch. Osgud, J. Kelly (Kelly, 1955), etc.). Domestic psychosemantics (V.F. Petrenko, etc.) models verbal categorial properties of consciousness. However, "at the position clearness of a problem of its constructive solution it is not proposed yet" (Artemyeva, 1999, 10). We develop semantic models and technology of research MSO of the subject (Dyakov, 2019, 2016 and - c) in a perspective of modern synergy approach. The person is considered in the vital field as an open circuit which self-organizes in interaction with other systems of the world and knowledge. MSO of the person develops on the basis of intentional-biological, sociallyarchetypic and cultural and historical semantic structures and mechanisms in space of personal experience of knowledge and understanding of values and the meaning of things and the ideas in the field of the public relations therefore IT opens and realizes itself as subject of life (Dyakov, 2016c). According to J. Kelly's thesis (Kelly, 1955), each person is a researcher. Experience of the person is based on direct elements of "sensual fabric" and is categorized in semantic verbal constructs and concepts (cause and effect logical or irrational patterns) which open algorithms and structure of understanding and judgment of people by it, things and the ideas of life. The personal semantic model of the world and itself in it and also meaning of life and self-realization - is its MSO own cognitive and motivational and value model. In verbal representation of experience of life, categorization and conceptualization of knowledge of experience, the subject seeks for the independent choice from variety of properties and qualities of things and the ideas of personally significant characteristics and their interpretation, building the system of understanding of the ideas and things according to THEIR properties and value (semantics of feelings and thoughts in MSO). These characteristics act in his consciousness as the system of concepts by means of which he can characterize himself as the personality and to explain 
conceptually. "Consciousness displays itself in a word as the sun in a small drop of water. The intelligent word is a microcosm of human consciousness" (Vygotsky, 1934: 318)). In turn the relations form the complete system of individual, selective, conscious communications of the personality with various parties of reality (V.N. Myasishchev, etc.). Therefore, the research of subjectness of the personality best of all gives in to study in linguistic (R. Kettel, G. Olport, etc.) and semantic (E.Yu. Artemyeva (1999), J. Kelly (Ke11u, 1955), Ch. Osgood, V.F. Petrenko, V.P. Serkin (2016), etc.) a methodological paradigm.

It is considered to be that (A. Maslow, etc.) and deep, natural (Aristotle, K. Goldstein, K. Rogers, etc.) need (motive, sense) of the person self-updating is topmost. It is process and result which reflects how the subject builds MSO and updates the motives values at different stages of a course of life (feature of semantic constructs and concepts (the values and meanings issued in thoughts and feelings)). In it the bypothesis of a research of rather youthful age consists.

In respect of development of semantic technology of a research of subjectness we offered a number of models and techniques (Dyakov, 2019, 2016a-c). The research objective - to define semantic constructs self-updating in modeling of personal identification.

\section{Methods and techniques of a research}

The sample was made by students of 3-5 courses of Sevastopol and Yalta, Russian Federation (218 people, 17-21 years.). The original experimental technique "Semantic Modelling of Self-organization of the Personality" ("SMSOP") is developed. Forms of a technique of "SMSL" are offered examinees (Dyakov, 2016c). At the heart of a technique semantic differential of Ch. Osgud. "SMSL" includes 66 dichotomizing scales constructs. This set of scales of linguistic constructs of MSO of the personality in space of sociocultural identification is received as a result of an empirical research, by means of the equipment of "repertoire lattices" of J. Kelly (see appendix 1; (N> 1000, age of 16-55 years. a psychometrics in works (Dyakov, 2016a, c)). Constructs the reflecting subject qualities are marked with an asterisk - them 43, 23 constructs background. The equipment of a self-assessment by comparison "images I am" ("I am-real" and "I am-ideal" (K. Rodgers, etc.) and also modeling of images of "The Selfupdated Personality" (SUP) and "Nonconformist" (NC) in aspect of subjectness is used. A set of constructs of "SMSL" can be built on concrete sample.

The SMSL procedure (the form - Appendix 1). Instruction. in the table the scales of semantic constructs disclosing personal characteristics are given. Polar scales, have the opposite sides. You need to perform the following tasks.

1. See all presented constructs, and note in the 1 st column "tick" from them 20. It the qualities which are most expressed at you. Designate the 1st column "I am-real". Range noted 20 constructs. A rank of the 1 st - the highest. Further estimate yourself "I am-real" on the ranged constructs, according to the scale shown above, from 1 to 7 points. Quality in a construct at the left in points from 1 to 3 , on the right - from 5 to 7.4 balls are average assessment. For example, "focus looseness": a rank 1 , through fraction assessment $2=1 / 2$, i.e. you purposeful.

2. Simulate, using 66 constructs, type of the personality "nonconformist" (NC) again (the concept of the NC is defined in the form). Again allocate 20 main constructs which, are peculiar to the $\mathrm{NC}$, and in column 2 range and estimate. Please, cover with a paper strip the previous column not to be guided by your results.

3. Simulate, using 20 constructs from 66 scales "the selfupdated personality" (SUP) (the concept of SUP is defined in the form). In the 3rd column range and make assessment. Please, cover the previous results.

4. Again, estimate yourself in aspect "I am-ideal" what you want to become. Allocate 20 constructs from 66 scales. In the 4th column range and make assessment. Please, cover the previous results.

The procedure of the choice of 20 qualities in each task, and then ranging of on them and estimations in points is necessary for allocation of constructs, semantic relevant for the personality. Technology of definition of repertoire constructs is also presented to J. Kelli (it is also possible to range constructs (Dyakov, 2016a, c)). It was important to us to receive subjectness constructs in self-updating of the personality. This matrix of constructs allows to build semantic modeling of different types of subjectness of the personality (tolerant, inclined to risk, the ideal psychologist, etc.) and in different ways (for example, to estimate itself in points on all constructs and to compare results of the offered scales: «I am-ideal», etc.) with the subsequent factorization. The presented model defines a possibility of empirical check.

The descriptive statistics and factor analysis were applied to processing of results of a research (a method main a component, a rotation method varimax with Kaiser normalization). The statistical SPSS v 21 package is used.

Presented in Appendix 1 formulations of poles of constructs are original, i.e. are received from results of filling of repertoire lattices of J. Kelli therefore cannot always look antonymous ("artistic nature - without manners", "creative mind - formalists"). However, the value of quality of the personality is defined easily what the expert procedure semantic estimates of data confirms.

In difference from "Big five" "Hexaco" received models of the personality, etc. in our researches the constructs were not factorized mathematically as qualities of the personality, and classified by MSO properties (Dyakov, 2016a, c).

\section{Results and their discussion}

By results of ranging of constructs "I am-real." (task 1) the following data of frequency analysis (tab. 1) are obtained. 
Table 1

The data of the frequency analysis of modeling "I-real".

\begin{tabular}{|c|c|c|c|c|c|c|c|c|c|c|c|c|c|c|c|c|c|c|c|c|}
\hline Scales & & & & & 1 & 2 & 3 & 4 & 5 & 6 & 7 & 8 & 9 & 10 & 11 & 12 & 13 & 14 & 15 & 16 \\
\hline Freque & & & & & 5 & 23 & 10 & 13 & 12 & 11 & 4 & 7 & 19 & 9 & 14 & 4 & 14 & 2 & 8 & 8 \\
\hline & & & & & & & & & & & & & & & & & \multicolumn{4}{|c|}{ Continuation of Table 1} \\
\hline 17 & 18 & & 19 & 20 & 21 & 22 & 23 & & 24 & 25 & 26 & 27 & 28 & 29 & 30 & & 31 & 32 & 33 & 34 \\
\hline \multirow[t]{2}{*}{16} & 10 & & 18 & 3 & 7 & 14 & 18 & & 5 & 4 & 5 & 5 & 18 & 10 & 12 & & 2 & 5 & 7 & 12 \\
\hline & & & & & & & & & & & & & & & & & \multicolumn{4}{|c|}{ Continuation of Table } \\
\hline 35 & 36 & & 37 & 38 & 39 & 40 & 41 & & 42 & 43 & 44 & 45 & 46 & 47 & 48 & & 49 & 50 & 51 & 52 \\
\hline \multirow[t]{2}{*}{1} & 12 & & 4 & 10 & 13 & 8 & 8 & & 1 & 8 & 11 & 0 & 5 & 0 & 4 & & 2 & 15 & 6 & 12 \\
\hline & & & & & & & & & & & & & & & & & \multicolumn{4}{|c|}{ Continuation of Table 1} \\
\hline 53 & & 54 & & 55 & 56 & 57 & & 58 & & 59 & 60 & 61 & & 62 & 63 & & 64 & 65 & & 66 \\
\hline 0 & & 6 & & 9 & 10 & 1 & & 8 & & 5 & 10 & 6 & & 6 & 0 & & 4 & 0 & & 0 \\
\hline
\end{tabular}

These indicators (the choice of scales "EmotionalityRestraint of feelings" ( $66 \%$ referred it to the first 10 ranks), "quiet, balanced - irascibility, nervousness", "sense of humor -lack of sense of humor", "fidelity, devotion, the good friend - treachery, unreliability", "the aspiration to be beautiful untidiness", "love to fine - lack of sense of beauty") speak about emphasis in semantic aspect of these respondents, in a self-assessment of an image "I am-real", the chosen semantic characteristics of the personality. Priority value the construct got "the aspiration to be beautiful - untidiness" where the maximum rank was noted by $20 \%$ of respondents. Also maximum rank met at constructs "Emotionality - Restraint of feelings", "Happy - unhappy" and to a lesser extent for constructs "Quiet, balanced - Irascibility, nervousness", "Artistic nature - Without manners", "Modesty, restraint - Impudence, bragging", "The intellectuality, erudition - Mediocrity", "Erudition - read A little", "Cultural wealth - Material values, prosaicness", "Beautiful externally, nice - Ugly", "Justice, honesty - Dishonesty". Youth aspects of intellectuality (mind), beauty and morality (honesty, justice, fidelity) and also happiness as full satisfaction with life interest. These aspects; intellectual, esthetic and moral were defined by us in other researches and are defined as aspects of motivation and feelings of the personality, and happiness and spirituality (cultural wealth) is defined as "the meaning-life ideological level" (see Clerks, 2015, 2016c). Also, the choice of construct No. 4 "wellbeing in private life - trouble" is characteristic of this sample, it makes $20 \%$, but not the most priority is defined as the $3 \mathrm{rd}$ rank, that is, but conventional. Construct No. 13 "spirituality, cultural wealth - material values, prosaicness" as it was noted above, at 14 elections, on the 1 st rank made $5.7 \%$, and on the 8 th $-17.1 \%$. Scales No. 45, 47, 53, 63,65 and 66 are not involved at all by respondents.
Factor analysis of results of modeling "I am-real" showed the following (tab. 2). The factor model for the purpose of viewing dispersion of data in a semantic field and determination of the main coordinates is constructed 2nd (this option on all tasks).

\section{Table 2}

Factor load table simulation "I-real".

1st factor: "emotional carelessness"

2 Emotionality - Restraint of feelings .778

3 Intelligence, erudition - Mediocrity, low intelligence 589

7 Gambling - Non-Gambling -.526

9 Calm, balanced - Short temper, restlessness, nervousness -.647

15 Loving, Sexual - Indifference, sexually uninterested .589

20 They are a positive ideal - they are the antipode of an ideal .507

39 Justice, Honesty - Dishonesty -.533

41 Caring - Indifferent -.507

54 Artistic nature - Disorder .513

61 Accuracy - Sloppy -.571

2nd factor: "strength of character"

1 Focus - Loose .669

8 Strength of character, will, stamina, hardness-Spinelessness, weak personality .557

10 Activity - Passivity .563

16 Curiosity, interested in new - Not interested in anything new .522

23 Loyalty, devotion, good friend - Betrayal, insecurity .749

56 Ability to achieve the goal - Inability to achieve the goal .786 60 Modesty, restraint - Impudence, bragging -.535

By results of a self-assessment of respondents of in points, on the scales allocated in ranging, in aspect "I amreal", the following data (tab. 3) are obtained. 
Table 3

These self-assessments real "an image I" in points.

\begin{tabular}{|c|c|c|c|c|c|c|c|c|c|c|c|c|c|c|c|c|}
\hline № Scales & 1 & 2 & 3 & 4 & 5 & 6 & 7 & 7 & 8 & 9 & 10 & 11 & 12 & 13 & 14 & 15 \\
\hline Frequen- & 5 & 23 & 10 & 13 & 12 & 11 & 4 & & 7 & 19 & 9 & 14 & 4 & 14 & 2 & 8 \\
\hline$\%-1$ & 0 & 8.57 & 5.7 & 0 & 8.5 & 11 & 0 & & 0 & 20 & 0 & 14.3 & 0 & 2.86 & 0 & 0 \\
\hline$\%-2$ & 14.3 & 20 & 17 & 25.7 & 14. & 5.7 & 5.7 & & 8.57 & 8.6 & 5.71 & 14.3 & 0 & 20 & 5.71 & 14 \\
\hline$\%-3$ & 0 & 5.71 & 5.7 & 5.71 & 11. & 5.7 & 7 & & 11.4 & 5.7 & 8.57 & 5.71 & 0 & 5.71 & 0 & 0 \\
\hline$\%-4$ & 0 & 2.86 & 0 & 5.71 & 0 & 8.6 & 5.7 & & 0 & 5.7 & 5.71 & 0 & 0 & 5.71 & 0 & 8.6 \\
\hline$\%-5$ & 0 & 5.71 & 0 & 0 & 0 & 0 & 0 & & 0 & 5.7 & 5.71 & 5.71 & 5.7 & 0 & 0 & 0 \\
\hline$\%-6$ & 0 & 8.57 & 0 & 0 & 0 & 0 & 0 & & 0 & 8.6 & 0 & 0 & 5.7 & 5.71 & 0 & 0 \\
\hline$\%-7$ & 0 & 14.3 & 0 & 0 & 0 & 0 & 0 & & 0 & 0 & 0 & 0 & 0 & 0 & 0 & 0 \\
\hline \multicolumn{17}{|c|}{ Continuation of Table } \\
\hline 16 & 17 & 18 & 19 & 20 & 21 & 22 & 23 & 24 & 25 & 26 & 27 & 28 & 29 & 30 & 31 & 32 \\
\hline 8 & 16 & 10 & 18 & 3 & 7 & 14 & 18 & 5 & 4 & 5 & 5 & 18 & 10 & 12 & 2 & 5 \\
\hline 2.86 & 37.1 & 5.7 & 25.7 & 8.57 & 0 & 5.71 & 11.4 & 0 & 0 & 0 & 0 & 11.4 & 11.4 & 0 & 0 & 5.71 \\
\hline 20 & 0 & 14 & 14.3 & 0 & 5.7 & 20 & 17.1 & 0 & 0 & 2.86 & 8.6 & 40 & 11.4 & 23 & 0 & 0 \\
\hline 0 & 0 & 8.6 & 5.71 & 0 & 8.6 & 11.4 & 20 & 0 & 5.71 & 0 & 0 & 0 & 0 & 5.7 & 5.71 & 0 \\
\hline 0 & 0 & 0 & 0 & 0 & 5.7 & 0 & 2.86 & 0 & 0 & 5.71 & 0 & 0 & 5.71 & 0 & 0 & 8.57 \\
\hline 0 & 0 & 0 & 0 & 0 & 0 & 2.86 & 0 & 0 & 5.71 & 0 & 0 & 0 & 0 & 5.7 & 0 & 0 \\
\hline 0 & 8.57 & 0 & 0 & 0 & 0 & 0 & 0 & 8.6 & 0 & 0 & 5.7 & 0 & 0 & 0 & 0 & 0 \\
\hline 0 & 0 & 0 & 5.71 & 0 & 0 & 0 & 0 & 5.7 & 0 & 5.71 & 0 & 0 & 0 & 0 & 0 & 0 \\
\hline \multicolumn{17}{|c|}{ Continuation of Table } \\
\hline 33 & 34 & 35 & 36 & 37 & 38 & 39 & 40 & 41 & 42 & 43 & 44 & 45 & 46 & 47 & 48 & 49 \\
\hline 7 & 12 & 1 & 12 & 4 & 10 & 13 & 8 & 8 & 1 & 8 & 11 & 0 & 5 & 0 & 4 & 2 \\
\hline 0 & 17.1 & 0 & 11 & 5.71 & 2.86 & 23 & 14.3 & 2.86 & 0 & 0 & 0 & 0 & 0 & 0 & 0 & 5.71 \\
\hline 0 & 8.57 & 2.86 & 17 & 0 & 14.3 & 8.6 & 8.57 & 14.3 & 0 & 11.4 & 5.71 & 0 & 5.71 & 0 & 5.7 & 0 \\
\hline 14 & 5.71 & 0 & 5.7 & 0 & 5.71 & 5.7 & 0 & 0 & 0 & 0 & 5.71 & 0 & 2.86 & 0 & 0 & 0 \\
\hline 0 & 0 & 0 & 0 & 0 & 5.71 & 0 & 0 & 5.71 & 2.9 & 0 & 20 & 0 & 0 & 0 & 0 & 0 \\
\hline 5.7 & 0 & 0 & 0 & 0 & 0 & 0 & 0 & 0 & 0 & 0 & 0 & 0 & 5.71 & 0 & 0 & 0 \\
\hline 0 & 2.86 & 0 & 0 & 5.71 & 0 & 0 & 0 & 0 & 0 & 11.4 & 0 & 0 & 0 & 0 & 0 & 0 \\
\hline 0 & 0 & 0 & 0 & 0 & 0 & 0 & 0 & 0 & 0 & 0 & 0 & 0 & 0 & 0 & 0 & 0 \\
\hline \multicolumn{17}{|c|}{ Continuation of Table } \\
\hline 50 & 51 & 52 & 53 & 54 & 55 & 56 & 57 & 58 & 59 & 60 & 61 & 62 & 63 & 64 & 65 & 66 \\
\hline 15 & 6 & 12 & 0 & 6 & 9 & 10 & 1 & 8 & 5 & 10 & 6 & 6 & 0 & 4 & 0 & 0 \\
\hline 5.71 & 0 & 2.86 & 0 & 0 & 8.57 & 5.71 & 0 & 0 & 0 & 20 & 0 & 2.86 & 0 & 5.71 & 0 & 0 \\
\hline 8.57 & 11 & 25.7 & 0 & 8.6 & 17.1 & 2.86 & 2.9 & 0 & 0 & 8.6 & 5.71 & 5.71 & 0 & 0 & 0 & 0 \\
\hline 8.57 & 5.7 & 0 & 0 & 8.6 & 0 & 8.57 & 0 & 5.71 & 5.71 & 0 & 0 & 0 & 0 & 5.71 & 0 & 0 \\
\hline 14.3 & 0 & 0 & 0 & 0 & 0 & 11.4 & 0 & 0 & 0 & 0 & 5.71 & 0 & 0 & 0 & 0 & 0 \\
\hline 0 & 0 & 0 & 0 & 0 & 0 & 0 & 0 & 0 & 8.57 & 0 & 0 & 0 & 0 & 0 & 0 & 0 \\
\hline 0 & 0 & 0 & 0 & 0 & 0 & 0 & 0 & 0 & 0 & 0 & 0 & 0 & 0 & 0 & 0 & 0 \\
\hline 5.71 & 0 & 5.71 & 0 & 0 & 0 & 0 & 0 & 17.1 & 0 & 0 & 0 & 2.86 & 0 & 0 & 0 & 0 \\
\hline
\end{tabular}

At the maximum number of elections by respondents of this sample of construct No. 2, the equal 23 choice, a part of respondents estimates themselves, first of all as emotional, but many do a self-assessment towards restraint of feelings. Only 1 person does average assessment 4 points (see tab. 3 ). Thus, we see considerable dispersion of indicators that shows subjective distinctions of individual characteristics of respondents which in the identical environment (training, in this case) have different features of estimation and interpretation of the personal properties. The maximum number of coincidence in assessment 1 point at these respondents have constructs No. 17 "Love for fine - Lack of sense of beauty" - 37.1\% (at the number of elections in ranging - 16) and No. 19 "Sense of humor - Lack of sense of humor" $-25.7 \%$ (at the number of elections in ranging -
18). At the same time the 2 nd persons. From 18 (5.71\%) speak about lack of sense of humor, and 3 people from 16 $(8.57 \%)$ speak about lack of sense of beauty. On construct No. 28 "The aspiration to be beautiful - Untidiness, ugliness", from 18 elections, assessment 2 points $-40 \%$ and 1 point $-11.4 \%$, in the absence of other estimates is made. That is, we see a priority of preferences of respondents. At the same time, the construct is constructed in the form of motivation, but not estimation of quality that marks out semantic aspect of activity of respondents.

Also 7 respondents gave an assessment 1 b. (from 19 people) on constructs No. 9 "Quiet, balanced - Irascibility, anxiety, nervousness"; 2 b. (from 14 people) No. 13 "Cultural wealth-Material values, prosaicness"; 2 b. (from 8 people) No. 22 "The developed intuition - the Undeveloped 
intuition". These features find expression in factor analysis of results of a self-assessment "I am-real." (in points) (tab.4).

Table 4

Table of factor loadings of a self-assessment "I am-real." (in points).

1st factor: "optimal relationships with others"

7 Gambling - Non-Gambling .713

9 Calm, balanced - Hot temper, anxiety, nervousness .630

13 Spirituality, spiritual values - Material values, earthliness .650

15 Loving, Sexual - Indifference, Disinterested Sexually -..508

17 Love for the beautiful - Lack of a sense of the beautiful - .523

29 Mutual assistance, friendliness - Unfriendliness, unfriendliness .648

39 Justice, Honesty - Dishonesty .579

41 Caring - Indifferent .836

48 Behavior Flexibility - Conservative .691

62 Compromise - Uncompromising .721

2nd factor: "Well-being in life"

4 Well-being in one's personal life - Adversity .588

14 Authoritative, respected - Non-authoritative, disrespectful .522

16 Curiosity, interested in the new - Not interested in anything new -.721

23 Fidelity, Reliability, Devotion- Betrayal, Insecurity .617

25 Professionalism, knows his job, specialist - Amateurism, incompetence .559

30 Self-organization - disorganization -.744

31 Is able to spend time interestingly - Cannot spend time .522

36 Beautiful in appearance, cute, charming - Ugly .519

37 Able to make money - Not able to earn .519

52 Has to himself - It is difficult for him to open -.598

56 Ability to achieve the goal - Inability to achieve the goal .706 60 Modesty, restraint - Impudence, bragging -..713

On the second task, in aspect of modeling of type of the identity of "nonconformist" (NC). The NC is an independent person who has the opinion, does not follow the tastes of others, creative search, personal understanding and the analysis of a situation, innovative decisions is peculiar to it. In this type, as well as in type of "the selfupdated personality" (SUP), properties of subjectness of the personality, that is independence are put into activities. However, in turn, it is possible to allocate also different types of the $\mathrm{NC}$ as different types of activity of the personality are possible: social and individual (subject at V.M. Rusalov), externally and internally directed (an extraversion and an introversion, according to $\mathrm{K}$. Jung), types (styles) of copingbehavior and the strategy of a recovery from a stress ( $R$. Lazarus, etc.), the directions of frustrating reactions of the "allowing" type (according to S. Rozencveyg), etc. Therefore, respondents of this sample and in the subsequent fairly had remarks in this occasion. That is, on some constructs it is difficult to make assessment because "disagreement" can have the different nature of subjectness realization (activity). Thus, in researches with use of matrixes of semantic differential, it is necessary to define accurately modelled type of the personality (subject) or to set several options (as it is stated above concerning the NC). Also, it emphasizes aspect of differentiation of concepts (semantics), and, therefore, types of the personality and her individual nature of life and activity.

In the second task the respondents in column No. 2 allocated again 20 main constructs of qualities which, according to them, are peculiar to the identity of the $\mathrm{NC}$, and ranged them and also estimated. By results of ranging the following data of a descriptive statistics (tab. 5) are obtained.

Table 5

Statistical data of modeling of "nonconformist" (ranks).

\begin{tabular}{|c|c|c|c|c|c|c|c|c|c|c|c|c|c|c|c|c|c|c|}
\hline \multicolumn{3}{|c|}{ Scales } & 1 & 2 & 3 & 4 & 5 & 6 & 7 & & 9 & 10 & 11 & 12 & 13 & 14 & 15 & 16 \\
\hline \multicolumn{3}{|c|}{ Frequency } & 10 & 16 & 18 & 8 & 10 & 20 & 5 & 2 & 8 & 17 & 13 & 5 & 10 & 9 & 0 & 18 \\
\hline & & & & & & & & & & & & & & & \multicolumn{4}{|c|}{ Continuation of Table 5} \\
\hline 17 & 18 & 19 & 20 & 21 & 22 & 23 & 24 & 25 & & 26 & 27 & 28 & 2 & 30 & & 32 & 33 & 34 \\
\hline \multirow[t]{2}{*}{6} & 10 & 5 & 4 & 25 & 7 & 2 & 12 & 10 & & 9 & 2 & 6 & ( & 12 & & 7 & 18 & 3 \\
\hline & & & & & & & & & & & & & & & \multicolumn{4}{|c|}{ Continuation of Table 5} \\
\hline 5 & 36 & 37 & 38 & 39 & & 40 & 41 & 42 & 43 & & 44 & 45 & 46 & 47 & 48 & 49 & 50 & 51 \\
\hline \multirow[t]{2}{*}{5} & 4 & 0 & 0 & 7 & & 0 & 0 & 8 & 9 & & 9 & 6 & 3 & 8 & 4 & 6 & 9 & 19 \\
\hline & & & & & & & & & & & & & & & \multicolumn{4}{|c|}{ Continuation of Table 5} \\
\hline & & 53 & 54 & 55 & & 56 & 57 & 58 & 5 & & 60 & 61 & & & 63 & 64 & 65 & 66 \\
\hline & & 10 & 12 & 21 & & 9 & 1 & 2 & & 3 & 2 & 0 & & 0 & 0 & 7 & 5 & 2 \\
\hline
\end{tabular}

Respondents mark out, first of all, subject qualities ("The leader, the organizer - Not capable to organize", "Strength of mind, will - Spinelessness", "Original-formal", "Independence - Conformality, subordination", "Intellectuality the Mediocrity, low intelligence", "Inquisitiveness - are not interested in anything new", "The outstanding personality Grey, ordinary-looking", "Emotionality - Restraint of feelings"). At the same time the only construct which was also noted in the 1st task of ranging in a self-assessment" I am- real", is construct No. 2 "Emotionality - Restraint of feelings" (16 elections). This construct is allocated to $40 \%$ of respondents (from 15 people) in the first 4 ranks, and $17.1 \%$ of these respondents noted its 1 st rank. At the same time $36 \%$ of respondents estimated this construct in the first 4 points. Thus, respondents of this category, in many respects, are focused on emotional aspect of life, finding in it sense. Together with construct No. 2 noted above, also constructs No. 55 of "Original-formal, conservative" $20 \%$ from 21 
choice and No. 33 "The outstanding personality - Grey, ordinary-looking" 20\% from 18 elections are most allocated with the 1 st rank. It the aspect of eccentricity together with an emotional coloring reveal. Scales No. 15, 29, 37, 38, 40, $41,61,64$ are not involved at all by respondents, that is are not significant for them in respect of modeling and estimation of the NC. As we see, respondent's peculiar understands characteristics of the NC. About it it is necessary to notice that use of a system of linguistic signs (thesaurus of personal qualities and properties) in assessment and modeling of the personality, we deal with abstract concepts, and the most generalized from them, and furthermore the designating abstract aspects of life (such as happiness, good breeding, etc.), presents considerable difficulties. But the person operates with these concepts bearing in themselves values (semantics) and, thus, understands the world and adapts in it. In this example, the NC are a type of the personality. But, as well as the personality is known by a set of definitions in psychology, the NC reflects a set of components of qualities of the personality. Naturally, it cannot but present difficulty in assessment and modeling of this type. Results of modeling and estimation of the NC, on this sample of respondents, are reflected by method of ranging of semantic constructs also in factor analysis (tab. 6).
Table 6

Table of factor loadings of modeling of the NC.

1st factor: "reasonable confidence"

4 Well-Being in Personal Life - Welfare, 636

5 Smart, have a sharp mind - Fools, stupid, 680

7 Gambling - Non-Gambling, 857

16 Curiosity, interested in the new - Not interested in anything new, 617

17 Love for the beautiful - Lack of a sense of beauty, 796

18 Reasonableness, Realism, Practicality - Impracticality, Idealism, Romance 723

24 Unchained, Free - Bound, Indecisive, 812

2nd factor: "optimal relationships and activities"

8 Strength of character, will, stamina, hardness - Spinelessness, weak personality -, 610

25 Professionalism, knows his job, specialist - Amateurism, incompetence -, 753

26 Shyness, shyness - Looseness, 680

28 The desire to be beautiful, the desire to like - Sloppy, ugliness, 530

35 Workable, businesslike - Apathetic, unassembled -, 629

39 Justice, Honesty - Dishonesty -, 653

44 Frankness, openness, truthfulness - Hypocrisy, secrecy, cunning, 616

46 Tenderness, softness - Rudeness, aggressiveness -, 595

By results of estimation of respondents of the $\mathrm{NC}$ in points, on the scales allocated in ranging, the following data of a descriptive statistics (tab. 7) are obtained.

\section{Table 7}

These estimations of "nonconformist" in points.

\begin{tabular}{|c|c|c|c|c|c|c|c|c|c|c|c|c|c|c|c|c|c|}
\hline Scales & 1 & 2 & 3 & 4 & & 5 & 6 & 7 & 8 & 9 & 10 & 11 & 12 & 13 & 14 & 15 & 16 \\
\hline Frequency & $\begin{array}{l}\mathrm{y} \quad 10 \\
\mathrm{y}\end{array}$ & 16 & 18 & 8 & & 10 & 20 & 5 & 24 & 8 & 17 & 13 & 5 & 10 & 9 & 0 & 18 \\
\hline$\%-1$ & 11.4 & 20 & 43 & 5.71 & & 7.1 & 54 & 8.57 & 34.3 & 0 & 28.6 & 17.1 & 0 & 5.71 & 5.71 & 0 & 28.6 \\
\hline$\%-2$ & 11.4 & 5.71 & 8.6 & 8.57 & & 1.4 & 2.9 & 5.71 & 31.4 & 8.6 & 11.4 & 2.86 & 8.6 & 8.57 & 11.4 & 0 & 22.9 \\
\hline$\%-3$ & 5.71 & 8.57 & 0 & 8.57 & & 0 & 0 & 0 & 2.86 & 5.7 & 2.86 & 5.71 & 0 & 5.71 & 8.57 & 0 & 0 \\
\hline$\%-4$ & 0 & 8.57 & 0 & 0 & & 0 & 0 & 0 & 0 & 0 & 5.71 & 5.71 & 0 & 2.86 & 0 & 0 & 0 \\
\hline$\%-5$ & 0 & 0 & 0 & 0 & & 0 & 0 & 0 & 0 & 0 & 0 & 5.71 & 0 & 0 & 0 & 0 & 0 \\
\hline$\%-6$ & 0 & 0 & 0 & 0 & & 0 & 0 & 0 & 0 & 8.6 & 0 & 0 & 5.7 & 5.71 & 0 & 0 & 0 \\
\hline$\%-7$ & 0 & 2.86 & 0 & 0 & & 0 & 0 & 0 & 0 & 0 & 0 & 0 & 0 & 0 & 0 & 0 & 0 \\
\hline & & & & & & & & & & & & & & & \multicolumn{3}{|c|}{ Continuation of Table } \\
\hline 17 & 18 & 19 & 20 & 21 & & 22 & 23 & 24 & 25 & 26 & 27 & 28 & 29 & 30 & 31 & 32 & 33 \\
\hline 6 & 10 & 5 & 4 & 25 & & 7 & 2 & 12 & 10 & 9 & 2 & 6 & 0 & 12 & 7 & 7 & 18 \\
\hline 5.04 & 8.4 & 4.2 & 3.36 & 21 & & 5.88 & 1.68 & 10 & 8.4 & 7.56 & 1.7 & 5.04 & 0 & 10 & 5.88 & 5.88 & 15 \\
\hline 5.71 & 0 & 5.71 & 5.71 & 43 & & 11.4 & 0 & 14 & 0 & 0 & 0 & 8.57 & 0 & 17 & 11.4 & 5.71 & 31 \\
\hline 2.86 & 0 & 8.57 & 0 & 23 & & 5.71 & 0 & 20 & 28.6 & 0 & 0 & 5.71 & 0 & 8.6 & 8.57 & 5.71 & 14 \\
\hline 8.57 & 8.6 & 0 & 0 & 5.7 & & 2.86 & 0 & 0 & 0 & 0 & 5.7 & 0 & 0 & 0 & 0 & 5.71 & 5.7 \\
\hline 0 & 14 & 0 & 5.71 & 0 & & 0 & 5.71 & 0 & 0 & 2.86 & 0 & 2.86 & 0 & 8.6 & 0 & 2.86 & 0 \\
\hline 0 & 0 & 0 & 0 & 0 & & 0 & 0 & 0 & 0 & 0 & 0 & 0 & 0 & 0 & 0 & 0 & 0 \\
\hline 0 & 5.7 & 0 & 0 & 0 & & 0 & 0 & 0 & 0 & 11.4 & 0 & 0 & 0 & 0 & 0 & 0 & 0 \\
\hline 0 & 0 & 0 & 0 & 0 & & 0 & 0 & 0 & 0 & 11.4 & 0 & 0 & 0 & 0 & 0 & 0 & 0 \\
\hline & & & & & & & & & & & & & & & \multicolumn{3}{|c|}{ Continuation of Table } \\
\hline 34 & 35 & 36 & 37 & 38 & 39 & 40 & 41 & 42 & 43 & 44 & 45 & 46 & 47 & 48 & 49 & 50 & 51 \\
\hline 3 & 5 & 4 & 0 & 0 & 7 & 0 & 0 & 8 & 9 & 9 & 6 & 3 & 8 & 4 & 6 & 9 & 19 \\
\hline 0 & 8.57 & 0 & 0 & 0 & 0 & 0 & 0 & 8.6 & 11.4 & 5.71 & 0 & 0 & 8.57 & 2.9 & 5.71 & 17.1 & 29 \\
\hline 8.57 & 0 & 5.7 & 0 & 0 & 2.9 & 0 & 0 & 5.7 & 8.57 & 20 & 11 & 0 & 14.3 & 0 & 0 & 8.57 & 26 \\
\hline 0 & 5.71 & 5.7 & 0 & 0 & 0 & 0 & 0 & 0 & 5.71 & 0 & 5.7 & 0 & 0 & 8.6 & 0 & 0 & 0 \\
\hline 0 & 0 & 0 & 0 & 0 & 17 & 0 & 0 & 8.6 & 0 & 0 & 0 & 0 & 0 & 0 & 0 & 0 & 0 \\
\hline 0 & 0 & 0 & 0 & 0 & 0 & 0 & 0 & 0 & 0 & 0 & 0 & 0 & 0 & 0 & 0 & 0 & 0 \\
\hline 0 & 0 & 0 & 0 & 0 & 0 & 0 & 0 & 0 & 0 & 0 & 0 & 8.57 & 0 & 0 & 5.71 & 0 & 0 \\
\hline 0 & 0 & 0 & 0 & 0 & 0 & 0 & 0 & 0 & 0 & 0 & 0 & 0 & 0 & 0 & 5.71 & 0 & 0 \\
\hline
\end{tabular}


Continuation of Table 7

\begin{tabular}{ccccccccccccccc}
\hline 52 & 53 & 54 & 55 & 56 & 57 & 58 & 59 & 60 & 61 & 62 & 63 & 64 & 65 & 66 \\
\hline 2 & 10 & 15 & 21 & 9 & 1 & 2 & 3 & 2 & 0 & 10 & 0 & 7 & 5 & 2 \\
\hline 0 & 20 & 26 & 48.6 & 14.3 & 0 & 0 & 0 & 0 & 0 & 0 & 0 & 11.4 & 2.86 & 0 \\
\hline 5.71 & 8.57 & 17 & 11.4 & 11.4 & 0 & 5.71 & 8.57 & 0 & 0 & 5.71 & 0 & 8.57 & 5.71 & 0 \\
\hline 0 & 0 & 0 & 0 & 0 & 2.9 & 0 & 0 & 0 & 0 & 0 & 0 & 0 & 0 & 5.7 \\
\hline 0 & 0 & 0 & 0 & 0 & 0 & 0 & 0 & 0 & 0 & 0 & 0 & 0 & 0 & 0 \\
\hline 0 & 0 & 0 & 0 & 0 & 0 & 0 & 0 & 5.7 & 0 & 0 & 0 & 0 & 5.71 & 0 \\
\hline 0 & 0 & 0 & 0 & 0 & 0 & 0 & 0 & 0 & 0 & 14.3 & 0 & 0 & 0 & 0 \\
\hline 0 & 0 & 0 & 0 & 0 & 0 & 0 & 0 & 0 & 0 & 8.57 & 0 & 0 & 0 & 0 \\
\hline
\end{tabular}

In the analysis of estimation of the $\mathrm{NC}$ in points we deal again with 20 constructs which are allocated in ranging. Constructs "The leader, the organizer - Not capable to organize, inclined to submit" are the most priority. All 25 people define presence of leadership and organizing skills in modeling of the NC. On construct No. 8 "Strength of mind, will, firmness, hardness - Spinelessness" (24), respondents are also uniform in the choice of qualities of strength of mind and will. Also, the priority of constructs "Originalformal" is allocated, "Independence - Conformality", "Intellectuality - the Mediocrity, low intelligence", "Inquisitiveness - are not interested in anything new", "The outstanding personality - Grey, ordinary-looking", "Emotionality - Restraint of feelings". Respondents mark out, first of all, subject qualities. At the same time, the only construct which was also noted in the 1st task of ranging in a self-assessment "I am-real" is construct No. 2 "Emotionality - Restraint of feelings" (16 elections). This construct is allocated to $40 \%$ of respondents (from 15 people) in the first 4 ranks, and $20 \%$ of these respondents noted its 1 st rank. At the same time, $36 \%$ of respondents estimated this construct in the first 4 points (see tab. 8).

Table 8

Constructs with the maximum number of elections.

\begin{tabular}{lc}
\hline No Constructs & Frequency \\
\hline 1 Purposefulness - Looseness & 19 \\
3 Intelligence - Mediocrity, Low Intelligence & 19 \\
5 Smart, have a sharp mind - Fools, dumb & 21 \\
8 Strength of character, will, perseverance - & 22 \\
Spinelessness, weak personality & 20 \\
16 Curiosity, interested in new - Not interested in & 24 \\
25 anything & \\
Professionalism, knows his job, specialist, master - & 15 \\
Dilettantism, incompetence & 13 \\
\hline 11 Readability - Little read & 13 \\
30 Self-organization - disorganization & 14 \\
35 Workable, business - Apathetic, unassembled & 13 \\
42 Strictness, exactingness - Softness, loyalty & 13 \\
47 Entrepreneurship, initiative - lack of initiative & \\
49 The desire to master the profession - Hope for help & \\
\hline
\end{tabular}

Thus, respondents of this category, in many respects, are focused on emotional aspect of life, finding in it sense. Together with construct No. 2 noted above, also constructs are most allocated with the 1 st rank: No. 55 "Originalformal" of $48.6 \%$ from 21 choice; No. 33 "The outstanding personality - Grey, ordinary-looking" $31 \%$ from 18 elections. It the aspect of eccentricity together with an emotional coloring reveal. Also, we see that in assessment 1 point at these respondents constructs No. 17 "Love for fine - Lack of sense of beauty" - 5.71\% (have the maximum number of coincidence at the number of elections in ranging - 16) and No. 19 "Sense of humor - Lack of sense of humor" - 5.71\% (at the number of elections in ranging 18). In the third task (see the instruction) respondents in column No. 3 should allocate again 20 main constructs of qualities which, according to them, are peculiar to "the selfupdated personality" (SUP), and ranged them and also estimated (by analogy with the previous task). By results of modeling of SUP, the following data of a descriptive statistics are obtained. The greatest number of elections by respondents are referred to scales of constructs No. 1, 3, 5, 8, 16, 25 and also, constructs No. 11, 30, 35, 42, 47, 49 are considerably expressed (see tab. 8). If to compare these constructs to constructs the chosen respondents in modeling by ranging of the NC, then scales No. 3, 8 and 16, that is characteristics of intelligence and informative motivation and also will power (character) have coincidence. But except these properties of SUP attribute qualities of "professionalism" (24 choice), defining, thus, SUP through the professional, business sphere. That is SUP reveals in characteristics of intelligence, will and professionalism. In structure of the personality, these qualities are defined by us as subject. In the $1 \mathrm{st}$, 2nd tasks of ranging (in a selfassessment "I am-real" and assessment of the NC) the basic allocated construct No. 2 "Emotionality - Restraint of feelings", at SUP, but according to respondents, it is not expressed. However, 6 people noted 1 and 2 points in assessment, i.e. defined free emotionality, but not restraint of feelings (there corresponds A. Maslow). Therefore, understanding of SUP in serious aspect of development of intelligence, will and professional abilities is peculiar to most of respondents. Scales No. 26, 38, 46, 60, 62, 63 are not involved at all by respondents, that is are not significant for them in respect of modeling and estimation of SUP. Scale No. 38 "Thrift - Wastefulness" is not involved by respondents, that is is not significant in assessment of characteristics, either the NC, or SUP though "I am-real" she participates in a self-assessment. And scale No. 63 "Strong physically - Weak" is not involved by respondents in assessment of characteristics of any of the estimated types. 
Results of modeling and estimation of SUP, on this sample of respondents, are reflected by method of ranging of semantic constructs also in factor analysis (Table 9).

\section{Table 9}

Table of factor loadings.

1st factor: "immediacy"

6 Independence - Conformity, subordination, 678

9 Calm, balanced - Hot temper, anxiety, nervousness, 632

17 Love of beauty - Lack of sense of beauty, 637

22 Developed Intuition - Undeveloped Intuition, 790

24 Unchained, Free - Bound, Indecisive, 723

29 Mutual assistance, friendliness - Unfriendliness, unfriendliness, 896

31 Is able to spend time interesting - Does not know how to spend time, 896

44 Frankness, openness, truthfulness - Hypocrisy, secrecy, cunning, 896

66 Beloved, pleasant - Unloved, bad, 896

\section{2nd factor: "self-confidence"}

2 Emotionality Restraint of feelings, 506

6 Independence - Conformity, subordination -, 596

9 Calm, balanced - Hot temper, anxiety, nervousness -, 588

13 Spirituality, spiritual values - Material values, earthliness -, 638

18 Reasonableness, realism, practicality, pragmatism - Impracticality, idealism, romantics, visionaries -, 523

20 They are a positive ideal - they are the antipode of an ideal -, 512

23 Fidelity, reliability, devotion, good friend - Betrayal, frivolity -, 590

27 Household - Ownerless -, 636

32 Cheerfulness, Optimism - Pessimism, 605

37 Able to make money - Not able to earn, 523

43 Self-Confidence - Insecurity, 742

56 Ability to achieve the goal - Inability to achieve the goal, 656

In the fourth task the respondents in column No. 4 should allocate again 20 main constructs of qualities which, according to them, define their image "I am-ideal" (Yai), and ranged them and also estimated (by analogy with previous). Indicators of the previous tasks asked to close them. By results of ranging of the semantic constructs defining characteristics "I am-ideal" the following data of a descriptive statistics are obtained. The greatest number of elections by respondents are referred to scales of constructs No. 1, 3, 4, 5, 6, 8, 10, 11, 21, 36 (tab. 10).
Table 10

Constructs with the maximum number of elections.

\begin{tabular}{clc}
\hline No & \multicolumn{1}{c}{ Constructs } & Frequency \\
\hline 1 & Focus - Looseness & 15 \\
3 & Intelligence, erudition - Mediocrity, low intelligence & 20 \\
4 & Well-being in Personal Life - Welfare & 20 \\
5 & Smart, have a sharp mind - Fools, dumb & 16 \\
6 & Independence - Conformity, subordination & 16 \\
8 & Strength of character, stamina - Spinelessness, weak & 16 \\
10 & personality & 16 \\
11 & Activity - Passivity & 15 \\
21 & Readability - Little read & 18 \\
37 & Leader, organizer - Not able to organize, inclined to & 15 \\
& \\
& obey & \\
\hline
\end{tabular}

Thus, respondents are most focused in the prospects of the development (and estimate constructs in the 1st, 2 and 3 points) on aspects wellbeing in private life $(57 \%)$, connecting it with own intellectuality $(52 \%)$, mind $(46 \%)$ and erudition $(43 \%)$, first of all, and also with qualities of focus (34\%), independence $(46 \%)$, strength of mind and will (40\%), activity (45\%), organizing leadership skills (51\%) and ability to earn money (43\%). In these elections, as well as in the choice of constructs for an experiment, trends of the modern reality which is naturally setting characteristics of values and the motivation and, therefore, influencing a selfassessment and "I am-concept" (self-understanding) are reflected. Nevertheless, noted by respondents of polarity of constructs of qualities, express aspects of subjectness, that is need of independence for activity for self-realization. Results of modeling "I am-ideal." To the given sample of respondents are reflected by method of ranging of semantic constructs in factor analysis (tab. 11).

Table 11

Table of factor loadings of modeling "I am-ideal."

1st factor: "nice to talk with"

2 Emotionality - Restraint of feelings, 817

26 Shyness, shyness - Looseness, 878

41 Caring - Indifferent, 662

52 Has to himself - It is difficult for him to open, 672

57 Serious attitudes to one's health, healthy lifestyle - Laxity, carefree attitude to health, 878

58 Grudge - Forgiveness, 794

60 Modesty, Restraint - Impudence, bragging, 878

2nd factor: "optimal communication"

3 Intelligence, erudition - Mediocrity, low intelligence, 656

4 Well-being in personal life - Welfare -, 520

5 Smart, have a sharp mind - Fools, stupid, 548

15 Loving, Sexual - Indifference, Disinterested in Sex, 684

23 Fidelity, reliability, devotion, good friend - Betrayal, insecurity, frivolity -, 549

27 Household - Ownerless -, 533

39 Justice, Honesty - Dishonesty -, 611

41 Caring - Indifferent -, 506

50 Ability to communicate, sociability - Inability to communicate, closed, fenced off -, 541

54 Artistic Nature - Immanence -, 501

66 Beloved, pleasant - Unloved, bad -, 525 
In the received results differences between modeling indicators "I am-ideal" and indicators of the NC and also SL and "I am-real" were noticed (tab. 12). The reliability of distinctions is confirmed statistically (Many-Whitney's Ucriterion). In aspect of a problem of self-realization of the subject distinctions (at the number of elections of a construct) indicators "I am-ideal" and the NC on many scales are noted: $1-6,8,9,12,15,16,18,19,22,23,26,27$, $30,33,34,36,37,41,43,44,49,51,53-56,62,65,66$; and also "I am-ideal" and SL: 4, 5, 6, 8, 10, 15, 16, 18, 19, 21-25, $28,30,31,33,34-36,39,42,45,46,48,49,51,56,58,59$, 61, 65. Therefore, respondents are not focused completely in self-realization on characteristics of the NC and SL. They, explain it with the fact that the last (Oil Company and SL) are ideal types of the personality with absolute qualities, and that him (respondents) the achievements kind of representing the following step of their life and development are important available (possible for implementation) for them. In it, therefore, influence of level of claims on a selfassessment and, apparently, at personal choice and decisionmaking is reflected (as understanding and assessment define the relation and decision-making). These characteristics open an essence of a research which results show relativity of a self-assessment in modeling of prospects of the personal future. What is connected with aspects of steps of prospect of self-realization in self-organization of life of the personality. In this connection it is necessary to remember U. James formula: Self-esteem (also a self-assessment) in direct ratio to success and in inverse proportion to claims. From here the higher than claim, the there is less opportunity to achieve success and the level of a selfassessment (self-esteem) is lower. Thus, seeking for maintaining self-esteem (own advantage), the personality shows the trends of regulation of level of claims supported by indicators of success of achievements. Nearly $93-97 \%$ of respondents show this dependence which has, obviously, sociocultural and logical and standard character. The personality is directed to self-realization and development, but thus focused on self-preservation of the identity. The same can be told concerning comparison of a selfassessment "I am-ideal" and "I am-real" (tab. 12).

Table 12

Comparative characteristics of assessment types (The frequency of the election of this construct is indicated).

\begin{tabular}{|c|c|c|c|c|c|c|c|c|c|c|c|c|c|c|c|c|}
\hline & \multicolumn{2}{|c|}{ Scales } & 1 & 2 & 3 & 4 & 5 & 6 & 7 & 8 & 9 & 10 & 11 & 12 & 13 & 14 \\
\hline & "I-r" & 1 & 5 & 23 & 10 & 13 & 12 & 11 & 4 & 7 & 19 & 9 & 14 & 4 & 14 & 2 \\
\hline & "NK" & 2 & 10 & 16 & 18 & 8 & 10 & 20 & 5 & 24 & 8 & 17 & 13 & 5 & 10 & 9 \\
\hline & "SP" & 3 & 19 & 4 & 19 & 12 & 21 & 10 & 1 & 22 & 9 & 9 & 15 & 11 & 10 & 11 \\
\hline Frequency & "I-id" & 4 & 15 & 3 & 20 & 20 & 16 & 16 & 2 & 16 & 10 & 16 & 15 & 10 & 12 & 10 \\
\hline
\end{tabular}

Continuation of Table 12

\begin{tabular}{ccccccccccccccccccccccccc}
\hline & 15 & 16 & 17 & 18 & 19 & 20 & 21 & 22 & 23 & 24 & 25 & 26 & 27 & 28 & 29 & 30 & 31 & 32 & 33 & 34 & 35 \\
\hline 1 & 8 & 8 & 16 & 10 & 18 & 3 & 7 & 14 & 18 & 5 & 4 & 5 & 5 & 18 & 10 & 12 & 2 & 5 & 7 & 12 & 1 \\
\hline 2 & 0 & 18 & 6 & 10 & 5 & 4 & 25 & 7 & 2 & 12 & 10 & 9 & 2 & 6 & 0 & 12 & 7 & 7 & 18 & 3 & 5 \\
\hline 3 & 2 & 20 & 7 & 12 & 7 & 8 & 10 & 7 & 8 & 6 & 24 & 0 & 5 & 4 & 3 & 13 & 3 & 8 & 4 & 6 & 13 \\
\hline 4 & 9 & 10 & 8 & 5 & 12 & 8 & 18 & 13 & 12 & 12 & 11 & 2 & 7 & 10 & 4 & 6 & 8 & 11 & 8 & 10 & 2 \\
\hline
\end{tabular}

\begin{tabular}{cccccccccccccccccccccccc}
\hline & 36 & 37 & 38 & 39 & 40 & 41 & 42 & 43 & 44 & 45 & 46 & 47 & 48 & 49 & 50 & 51 & 52 & 53 & 54 & 55 & 56 \\
\hline 1 & 12 & 4 & 10 & 13 & 8 & 8 & 1 & 8 & 11 & 0 & 5 & 0 & 4 & 2 & 15 & 6 & 12 & 0 & 6 & 9 & 10 \\
\hline 2 & 4 & 0 & 0 & 7 & 0 & 0 & 8 & 9 & 9 & 6 & 3 & 8 & 4 & 6 & 9 & 19 & 2 & 10 & 12 & 21 & 9 \\
\hline 3 & 8 & 6 & 0 & 4 & 2 & 6 & 14 & 9 & 3 & 8 & 0 & 13 & 11 & 13 & 9 & 16 & 6 & 7 & 3 & 3 & 17 \\
\hline 4 & 15 & 8 & 2 & 9 & 4 & 5 & 4 & 12 & 4 & 4 & 4 & 12 & 2 & 3 & 12 & 3 & 4 & 4 & 5 & 4 & 5 \\
\hline
\end{tabular}

\begin{tabular}{|c|c|c|c|c|c|c|c|c|c|c|}
\hline & 57 & 58 & 59 & 60 & 61 & 62 & 63 & 64 & 65 & 66 \\
\hline 1 & 1 & 8 & 5 & 10 & 6 & 6 & 0 & 4 & 0 & 0 \\
\hline 2 & 1 & 2 & 3 & 2 & 0 & 10 & 0 & 7 & 5 & 2 \\
\hline 3 & 2 & 0 & 7 & 0 & 3 & 0 & 0 & 12 & 4 & 3 \\
\hline 4 & 2 & 6 & 0 & 2 & 0 & 0 & 0 & 10 & 0 & 6 \\
\hline
\end{tabular}

The SMSL equipment gives the chance to define a difference between these types "images I". Besides it can be used in other option of work when examinees do not make ranging, and estimate themselves on 66 scales in aspect of a self-assessment "I am-ideal" and "I am-real.". The specified characteristics have applied value for personal advisory and correctional work with respondents.

Scale No. 59, 60, 61, 63, 65 is not enough or are not involved by respondents at all, that is they are not significant for them in respect of modeling and estimation "I am-ideal" (Table 13).

Table 13

Constructs not involved by respondents.

59. Stubbornness, intransigence - Obedience, unpretentiousness

60. Modesty, restraint - Impudence, bragging

61. Accuracy - Sloppy

63. Strong physically - Weak physically

65. Cultural, educated - Lack of culture 
Summary results of factor analysis for all tasks are presented in Table 14.

Table 14

Factor Analysis Summary.

The results of the simulation "I-real"

\begin{tabular}{ll}
\hline 1st: "emotional carelessness" & $\begin{array}{l}\text { 2nd factor: "strength of } \\
\text { character" }\end{array}$ \\
\hline
\end{tabular}

Self-assessment results of "I-real" (in points)

1st factor: "optimal relations with 2nd factor: "well-being in life" others"

Nonconformist Modeling Results

1st factor: "pleasant in communica- 2nd factor: "optimal

tion" communication"

"SP" simulation results

1st factor: "immediacy" 2nd factor: "self-confidence"

The results of modeling "I-ideal"

1st factor: "pleasant in 2nd factor: "optimal commu-

communication" nication"

These results of factor analysis show that to respondents of sample emphasis of attention in a self-assessment and assessment of self-realization on the following aspects is characteristic. It is the sphere of communication in which they are desired and significant, pleasant and loved, capable to realize the ideas. Also, it is emotional security and spontaneity of expression of emotions as qualities of the personality, trait of character, disposing to pleasure and satisfaction. Further, it is the strong-willed qualities of character defining selfconfidence. Important aspect of estimation and orientations of respondents is the factor of "wellbeing in life".

\section{Conclusion}

The person, acting as the personality in society, "designs" the world, i.e. brings into the system of knowledge of the world. The conscious system organization of this information is under construction it by understanding of value of things and the ideas of the world and determination of their value and meaning of life in general that allows it to be the subject

\section{References}

Artemyeva E.Yu. (1999). Fundamentals of the psychology of subjective semantics. Moscow: Science; Sense. (in Russian).

Bandura A. (2017). (ed.). Psychological modeling: Conflicting theories. Transaction Publishers.

Bar M. (2007). The proactive brain: Using analogies and associations to generate predictions. Trends in Cognitive Sciences. 11, 7, 280-89. CrossRef/Google Scholar. PubMed

Barrett L.F. (2009). The future of psychology: Connecting mind to brain. Perspectives in Psychological Science. 4, 326-39.

Bohm D. (2010). Causality and chance in modern physics. Moscow: Krasand. (in Russian).

Brushlinsky A.V. (2002). Psychology of the subject: individual and the group. Psychological Journal. 23, 1, 72-80. (in Russian).

Clark A. (2013). Whatever next? Predictive brains, situated agents, and the future of cognitive science. Behavioral and Brain Sciences. 36, 3, 181-204 DOI: https://doi.org/10.1017/S0140525X12000477

Dyakov.S.I. (2016). Semantic constructs of subject self-organization of of life. It defines relevance of semantic approach in research MSO of the subject (7). Semantic standards of selfrealization are integrated into "I am-concepts" of the personality and act as reference points of MSO of the subject. By means of the original SMSL equipment, semantic models of MSO of the personality were received and subject characteristics are defined. Comparative data of constructs of self-realization (in aspect "I am-ideal") and self-updating (SU) show that though SL and is reference (ideal) a model of achievements of the personality (according to A. Maslow, etc.), semantics of MSO of the subject reveals in orientations on near achievable aspects of prospect of life. Results of sample, along with the disclosed individual characteristics, showed statistical integrative features of subject MSO in orientations to semantic constructs of self-realization: emotional spontaneity and, at the same time, strength of mind and self-confidence and also communication and wellbeing in life (connected with intellectuality). These factors reflect functional specifics of semantics of motivation in MSO (emotional, strong-willed and intellectual parties) and also social aspect of the relations which are integrated in semantics of wellbeing of life. Obviously, it is connected with the fact that constructs of modeling open the social and role repertoire. However, in an expanded research it is revealed that the subject sphere also reflects the sociocultural nature of the organization of activity of the personality (Dyakov, 2016c).

The technique of "SMSL" can also be used in other options when examinees do not make ranging, and estimate themselves in aspect of a self-assessment "I am-ideal" and "I am-real" on all scales and model other types of the personality (friend, the beloved, etc.). A set of constructs of "SMSL" can be built on concrete sample.

Use of the SMSL equipment in a research nonverbal semantic MSO of the subject and also comparative characteristics reflecting to the MSO loudspeaker of the personality in different age stages and depending on specifics of professional, cultural and vital identification of the person is perspective (Dyakov, 2016 c).

the personality. Psycholinguistics questions. 1 (27), 89-104. (in Russian).

Dyakov.S.I. (2016). Self-organization in the system of psychological criteria of definition of the person as subject of life. Siberian psychological magazine. 59, 6-21. (in Russian).

Dyakov.S.I. (2016). Psychosemantics of self-organization of the person as subject of life. Fundamentals of psychology of the subject: Monograph. Saint Petersburg: Avenue Sciences. (in Russian).

Dyakov.S.I. (2020). Semantic Representation of Social and Role Identification in Subject Self-Organization of Personality. Psycholinguistics. 27(1), 52-79. https://doi.org/10.31470/2309-1797-2020-27-1-52-79

Farmer T.A., Brown M. \& Tanenhaus M.K. (2013). Prediction, explanation, and the role of generative models in language processing. Published online by Cambridge University Press. 36, 3, 211-212. DOI: https://doi.org/10.1017/S0140525X12002312

Fodor J.A. (1987). Psychosemantics: The problem of meaning in the philosophy of mind. The MIT press. 
Fogelson R.D. (1982). Person, Self, and Identity: Some Anthropological Retrospects, Circumspects, and Prospects. In: Lee B. (eds) of Psychosocial Theories of the Self. Path in Psychology. Springer, Boston, MA.

Heylighen F. (2011). Self-organization of complex, intelligent systems: an action ontology for transdisciplinary integration. Integral Review. 134, 139.

Hirsh J.B., Mar R.A., Peterson J.B. (2013). Personal narratives as the highest level of cognitive integration. Behavioral and Brain Sciences. Cambridge University $\quad$ Press. $10 \quad$ May. DOI: https://doi.org/10.1017/S0140525X12002269

Hockenmaier J. (2003). Parsing with Generative Models of PredicateArgument Structure. Association for Computational Linguistics. In book Proceedings of the 41st Annual Meeting on Association for Computational Linguistics. 1, 359-366. https://doi.org/10.3115/1075096.1075142

Karakozov S.D., Ryzhova N.I. (2019). Information and education systems in the context of digitalization of education. Zhurnal SFU. Gumanitarnyye nauki [Journal of SFU. Humanitarian sciences]. 9, 359-366.

Kelly G.A. (1955). The psychology of personal constructs. V. 1-2. New York: Norton.

Klochko V.E. (2005). Self-organization in psychological systems: problems of the formation of the mental space of an individual (introduction to trans-spectral analysis). Tomsk: TSU. (in Russian).

Koestern R., Hope N.A. (2014). Self-determination theory approach to goals. In M. Gagne (Ed.). The Oxford Handbook of Work Engagement, Motivation, and Self-Determination heory. doi: 10.1093/oxfordhb/9780199794911.001.0001.

Leskov L.V. (2008). Unknown Universe. Moscow: Publishing house LCI. (in Russian).

Levine D.S. (2018). Introduction to neural and cognitive modeling. Routledge.
Pirozhkova S.V. (2018). Forecasting and its place in the system of scientific knowledge. Problems of Philosophy. 11, 118-129. (in Russian).

Podoprigora A.V. (2016). Generator of reality: information and mechanisms of self-organization. Antinomies. 4, 17-32. (in Russian).

Richardson, M. J., Dale, R., \& Marsh, K. L. (2014). Complex dynamical systems in social and personality psychology: Theory, modeling, and analysis. In H. T. Reis \& Judd C.M. (Eds.). Handbook of research methods in social and personality psychology. 253-282. Cambridge University Press.

Ryan R.M., Deci E.L. (2017). Self-determination theory: Basic Psychological Needs in Motivation Development and Wellnessi. New York, NY: Guilford Press.

Sergienko E.A. (2013). The problem of the correlation of the concepts of subject and personality. Psychological Journal. 34, 2, 5-16. (in Russian).

Serkin V.P. (2016). Psychosemantics: textbook and workshop for undergraduate and graduate programs. Moscow: Yurayt Publishing House. (in Russian).

Shadrikov V.D. (2017). Neocognitive Psychology: Monograph. Moscow: Universitetskaya book. (in Russian).

Tatenko V.A. (1996). Psychology in the subjective dimension. Moscow: Ed. Center of "Enlightenment". (in Russian).

Vygotsky L.S. (1934). Thinking and speech. Moscow: Sotsekgiz. (in Russian).

Wang, Q. (2011). Autobiographical Memory and Culture. Online Readings in Psychology and Culture. 5(2). https://doi.org/10.9707/2307-0919.1047

Whitehead N.L., M. Wesc. (2012). Human no more: Digital subjectivities, unhuman subjects, and the end of anthropology. University Press of Colorado.

M.'s Whittingham(2018). Identity and Self-Determination. In book: The Self and Social Relations. DOI: 10.1007/978-3-319-77246-2_7

Znakov V.V. (2016). Psychology of understanding the human world. Moscow: Publishing house "Institute of Psychology RAS". (in Russian). 


\section{Appendix 1}

Form of a technique of "SMSL".

\begin{tabular}{|c|c|c|c|c|}
\hline \multicolumn{5}{|c|}{ Psychosemantic modeling } \\
\hline 1 & № $\quad$ Assessment: 1 & 5 & $23 \quad 3$ & 4 \\
\hline & $1 * \quad$ Purposefulness & Looseness & & \\
\hline & Emotionality & Restraint of feelings & & \\
\hline & $3 *$ Intellectuality, erudition & $\begin{array}{l}\text { Mediocrity, } \\
\text { low intelligence }\end{array}$ & & \\
\hline & Wellbeing in private life & Trouble & & \\
\hline & $5 * \quad$ Clever, have sharp mind & Fools, stupid & & \\
\hline & $6 * \quad$ Independence & Conformality, subordination & & \\
\hline & Hazardous & Not hazardous & & \\
\hline & $8 *$ Strength of mind, will, firmness, hardness & $\begin{array}{l}\text { Spinelessness } \\
\text { weak personality }\end{array}$ & & \\
\hline & $9 \quad$ Quiet, balanced & Irascibility, nervousness & & \\
\hline & $10 *$ Activity & Passivity & & \\
\hline & $11 *$ Erudition & Read a little & & \\
\hline & $12 *$ Concentration & Not concentration & & \\
\hline & 13 Spirituality, cultural wealth & Material values, & & \\
\hline & $14 *$ Authoritative, dear & Unauthoritative, not dear & & \\
\hline & 15 Loveful, sexual & Not sexual & & \\
\hline & $16 *$ Inquisitiveness, are interested in new & Are not interested in anything new & & \\
\hline & 17 Love for fine & Lack of sense of beauty & & \\
\hline & $18 *$ Judiciousness, realism, practicality, pragmatism & Impracticality, idealism, romantics, visionaries & & \\
\hline & 19 Sense of humor & Lack of sense of humor & & \\
\hline & $20 \quad$ Are a positive ideal & Are an ideal antipode & & \\
\hline & $21 *$ Leader, organizer & Inclined to submit & & \\
\hline & 22 The developed intuition & Undeveloped intuition & & \\
\hline & $23 *$ Fidelity, reliability, devotion, good friend & Treachery, unreliability, levity & & \\
\hline & 24 Relaxed, free in communication & Held down, indecisive, bashful, timid & & \\
\hline & $\begin{array}{l}25 * \begin{array}{l}\text { Professionalism, the business, the expert, the master } \\
\text { knows }\end{array}\end{array}$ & Amateurishness, incompetence & & \\
\hline & $26 *$ Creative mind & Formalists & & \\
\hline & $27 *$ Economic & Thriftless & & \\
\hline & $28 *$ The aspiration to be beautiful, desire to be pleasant & Untidiness, ugliness & & \\
\hline & 29 Mutual aid, friendliness & Not friendliness, unfriendliness & & \\
\hline & $30 *$ Organization & Disorganization & & \\
\hline & $31 *$ Is able to spend time interestingly & Is not able to spend time & & \\
\hline & $32 *$ Cheerfulness, optimism & Pessimism & & \\
\hline & $33 *$ Outstanding personality, extraordinary & "Gray", ordinary-looking & & \\
\hline & $34 *$ The punctuality, does not love insignificant talks & Spend time in vain & & \\
\hline & $35 *$ Efficient, efficient & Apathetic, not collected & & \\
\hline & $36 \quad$ Beautiful externally, nice, charming & Ugly & & \\
\hline & $37 *$ Are able to earn money & Not capable to earn & & \\
\hline & $38 *$ Thrift & Wastefulness & & \\
\hline & $39 *$ Justice, honesty & Dishonesty & & \\
\hline & $40 \quad$ Good breeding & Bad manners & & \\
\hline & $41 \quad$ Careful & Indifferent & & \\
\hline & $42 *$ Severity, insistence & Softness, loyalty & & \\
\hline & $43 *$ Self-confidence & Uncertainty & & \\
\hline & $44 \quad$ Frankness, openness, truthfulness & Hypocrisy, reserve, cunning, hypocrisy & & \\
\hline & $45 *$ Vanity, self-importance, arrogance, intolerance & Simplicity, tolerance to others & & \\
\hline & $46 \quad$ Tenderness, softness & Roughness, aggression & & \\
\hline
\end{tabular}




\begin{tabular}{|c|c|c|c|c|}
\hline \multicolumn{5}{|c|}{ Psychosemantic modeling } \\
\hline $1 \quad$ № & $2 \quad 3 \ldots 4 \ldots 5$ & $5 \quad 6$ & 23 & 4 \\
\hline $47 *$ & Enterprise, initiative & Lack of initiative & & \\
\hline $48 *$ & Flexibility of behavior & Conservatism & & \\
\hline $49 *$ & The aspiration to seize a profession & Hope for the help & & \\
\hline 50 & Ability to communicate, sociability & Inability to communicate, closed & & \\
\hline $51 *$ & Self-development, improvement of abilities, knowledge & Lack of aspiration to develop & & \\
\hline 52 & Wins & Difficultly for it to open & & \\
\hline $53 *$ & Ability to attract interest, to draw attention & Inability to interest & & \\
\hline $54 *$ & Artistic nature & Without manners & & \\
\hline $55 *$ & Original & Formal, conservative & & \\
\hline $56 *$ & Ability to achieve the objective & Inabilities to achieve the objective & & \\
\hline $57 *$ & Serious attitude towards the health, healthy lifestyle & Carefree attitude towards health & & \\
\hline 58 & Rancor & Ability to forgive & & \\
\hline $59 *$ & Obstinacy, obstinacy & Complaisance, unpretentiousness & & \\
\hline $60 *$ & Modesty, restraint & Impudence, bragging & & \\
\hline $61 *$ & Accuracy & Untidiness & & \\
\hline $62 *$ & Make a compromise & Uncompromising stand & & \\
\hline 63 & Strong physically & Weak & & \\
\hline $64 *$ & Happy & Unhappy & & \\
\hline 65 & Cultural & Bad manners & & \\
\hline 66 & Favorite, pleasant & Unloved, bad & & \\
\hline
\end{tabular}

The self-updated personality - the person who disclosed the potentials of abilities, reached top in the self-realization (for example, outstanding persons: politicians, actors, scientists, public figures).

The nonconformist is an independent person who has the opinion, does not follow the tastes of others, is inclined to creative search, innovative decisions. 